Canadian Journal of Higher Education Revue canadienne d'enseignement supérieur

Volume 45, No. 3, 2015, pages 15 - 33

\title{
Developing Graduate Students' Self-Efficacy with Learner-Centred Lecturing
}

Meagan Troop

University of Waterloo

Lauren Wallar \& Erin Aspenlieder

University of Guelph

\begin{abstract}
This paper presents the findings of a mixed-method case study conducted at the University of Guelph on the relationship between practice lecturing and graduate student self-efficacy. Building on the work of Boman (2013), and using surveys and individual interviews, we measured and characterized the perceived changes in graduate students' self-efficacy in learner-centred lecturing. Our research question was: In what ways, if any, does microteaching contribute to participants' perceived self-efficacy in learner-centred lecturing? Our results and discussion reveal that practice increases self-efficacy with respect to the design, facilitation, and assessment of learner-centred lectures, and is a vital component to graduate student teaching development programming.
\end{abstract}

\section{Résumé}

Cet article présente les résultats d'une étude de cas axée sur des méthodes mixtes, menée à l'Université de Guelph et portant sur les relations entre la pratique de l'exposé magistral et l'auto-efficience des étudiants des cycles 
supérieurs. En nous appuyant sur les recherches de Boman (2013), et au moyen de sondages et d'entrevues individuelles, nous avons mesuré et caractérisé les changements perçus quant à l'auto-efficience des étudiants des cycles supérieurs relativement aux exposés magistraux centrés sur l'apprenant. Notre question de recherche était la suivante : Le cas échéant, de quelles manières le microenseignement contribue-t-il à l'auto-efficience perçue par les participants eux-mêmes en situation d'exposés magistraux centrés sur l'apprenant? Nos résultats et notre discussion révèlent que la pratique augmente l'auto-efficience en matière d'élaboration, de facilitation et d'évaluation des exposés magistraux centrés sur l'apprenant. Il s'agit d'une composante primordiale des programmes de formation en enseignement pour étudiants des cycles supérieurs.

\section{Introduction}

The University of Guelph is a mid-sized, comprehensive university in Ontario, Canada, where learners and learning are prioritized in the university's mission statement. The university emphasizes "learner-centredness" as an approach to learning that requires learners to actively engage in constructing meaning (Weimer, 2002).

Open Learning and Educational Support (OpenEd) supports teaching and learning at the University of Guelph. With approximately 2,200 graduate students, OpenEd provides teaching development opportunities and programs for graduate students, including workshops, a graduate course on teaching and learning, the Instructional Skills Workshop, and conferences. With an increased recognition of not only the need to assess programs for their impact on teaching and learning, but also to use collected data to "deliberately ... improve practice" (Gravobe et al., 2012, p. 8), we undertook this study with the twin aims of assessing the impact of a workshop structure within our teaching development program for graduate students and modifying the program based on our findings.

\section{Literature Review}

Our project took inspiration from the call in Boman's 2013 article, "Graduate Student Teaching Development: Evaluating the Effectiveness of Training in Relation to Graduate Student Characteristics," for "future research . . . to help understand the contribution of ongoing educational programming to the development of graduate students as teachers" (Boman, 2013, p. 111). Boman's study investigated the effectiveness of a workshop that included practice teaching and feedback for graduate students with different degrees of experience in teaching, with a specific focus on international graduate students. Specifically, our study was guided by the following research question: In what ways, if any, does microteaching contribute to participants' perceived self-efficacy in learner-centred lecturing?

While we recognize the body of work on teaching graduate students to teach, which advocates for practice teaching, mentorship, and critical reflection as key components of effective graduate student teaching development (Aspenlieder \& Rawn, 2014; Prieto \& Meyers, 2001), we wanted to explore the contribution of workshops to graduate student teaching development and consider how the workshop structure could be modified to include the key components of practice and critical reflection. The literature reflects 
the value of practice teaching for graduate student teaching development, both for the acquisition of teaching skills and for the development of teaching self-efficacy (Dimitrov et al., 2013; Boman, 2008; Prieto \& Altmaier, 1994; Salinas, Kozuh, \& Seraphine, 1999). Bandura (1977) defines self-efficacy as "the conviction that one can successfully execute the behaviour required to produce the outcomes" (p. 193). Further to that point, he proposes that efficacy is enhanced by successfully performing tasks, observing others perform tasks and verbal encouragement.

Previous studies on program duration indicate that both short and long teaching development programs have a positive impact on teaching self-efficacy and learner-centred approaches in the classroom (Dimitrov et al., 2013), particularly programs that include practice components. Similar work on interdisciplinary and disciplinary teaching support programs suggests that graduate students successfully develop generic teaching skills, such as reflective practice or crafting a teaching philosophy, in both interdisciplinary and disciplinary groups (Heenan \& Jerich, 1993; Loughran, 2002). Given the range of skills that graduate students might develop related to teaching, and recognizing the success of both longer and shorter practice teaching programs in increasing graduate student self-efficacy and learner-centred strategies, our research focused on the development of the particular teaching competency of lecturing. With a range of teaching competencies and skills that teaching development programs support (see the Teaching Assistant and Graduate Student Advancement Special Interest Group of the Society for Teaching and Learning in Higher Education for a comprehensive list of teaching assistant competencies), we selected lecturing to consider the impact of practice on developing graduate student self-efficacy in this particular instructional skill rather than all, or undefined, instructional skills that might be of use to developing instructors.

Specifically, we focused on the development of graduate students' self-efficacy with learner-centred lecturing. Learner-centred instruction "couples a focus on individual learners ... with a focus on learning (the best available knowledge about learning and how it occurs and about teaching practices that are most effective in promoting the highest levels of motivation, learning and achievement for all learners)" (McCombs \& Whisler, 1997, p. 9). With the vast body of literature evidencing the impact of active learning on deep learning, and the concomitant evidence evincing the hazards of traditional lecturing (deWinstanley \& Bjork, 2002; Knight \& Wood, 2005; Prince, 2004; Wilson \& Korn, 2007), the curriculum we developed for the workshop included in this study focused on the application of learning outcomes and participatory learning activities within the lecture setting. Our goal was to have participants practice and reflect on, and thus gain selfefficacy and familiarity with, learner-centred lecturing. With our interest in considering how workshop format might impact the participants' experience, we researched the impact of practice teaching, relative to a typical workshop setting, on participant self-efficacy in learner-centred lecturing.

\section{Methodology}

\section{Workshop Overview}

In the winter term of 2014, 12 graduate students participated in a workshop titled "Learner-Centered Lectures" as part of the Graduate Student Teaching Development Pro- 
gram at the University of Guelph. The Learner-Centered Lecture workshop series included four two-hour workshops, which were held over a period of four consecutive weeks and were facilitated by Erin Aspenlieder. The first workshop introduced and modeled guiding principles for designing a learner-centred lecture. In the remaining three workshops, students planned and delivered a 10-minute lecture, and gave and received peer feedback.

\section{Study Recruitment}

Ethics clearance was received in March 2014 from the University of Guelph's Research Ethics Board (REB), after which graduate students were recruited via email. The letter of information and the survey (see Appendix) were included in the email. Additional ethics clearance was sought from REB in November 2014 to include individual interviews. Participants were recruited via email in January 2015 with an amended Letter of Information and Consent Form.

\section{Data Collection}

Data were collected using surveys and individual interviews. When the 12 participants arrived for the workshop, they received the letter of information and two copies of the survey. The survey consisted of a 10-point scale, adapted from Boman's "TA Self-efficacy Scale" (Boman, 2008) to evaluate perceived self-efficacy on 15 teaching parameters, as well as five open-ended questions related to participants' teaching skills and behaviours. Each participant assigned a numeric identifier to their surveys, so the surveys could be matched while maintaining anonymity. The 12 participants completed the survey three times: at the beginning and end of the first workshop, and at the end of the fourth workshop.

Participants were invited to take part in individual follow-up interviews in January 2015 to probe more deeply into their experience (Patton, 2002). Interviews with the six consenting participants lasted approximately 20 minutes and were held in an office at the University of Guelph. Interviews were conducted by Meagan Troop and were recorded using Garage Band software. The audio files were transcribed and identifying information was replaced with pseudonyms.

\section{Quantitative Data Analysis}

Quantitative matched participant scores from the first and second surveys, and from the second and third surveys, were analyzed using the non-parametric Friedman test for repeated ordinal measures ("Friedman test in SPSS Statistics," 2013). The dependent variables were the ordinal 10-point Likert scale scores for the three surveys. The independent variable was the self-efficacy parameter. If the Friedman test was significant $(p<$ 0.05), then the scores were analyzed using a Wilcoxon signed-rank post-hoc test to compare the scores from the first and second survey (workshop) and the second and third survey (practice). The significance level was adjusted using a Bonferroni correction for two comparisons to $p<0.025$. Median and first and third quartile values were determined for each self-efficacy parameter. Data was analyzed using SPSS, Version 22.0. 


\section{Qualitative Data Analysis}

Qualitative responses were analyzed to identify patterns and construct categories within the open-ended survey responses and interview data set using a grounded theory approach to interpret the lived experiences of the participants (Gibbs, 2007; Moustakas, 1994). Both etic (theory-driven) and emic (data-driven) codes were generated and used in open coding of the survey responses by all three authors, which enabled us to "contrast, compare, analyze, and bestow patterns upon them" (Miles \& Huberman, 1994, p. 7). After open coding, the original list of 66 codes was collapsed to a final list of 18 codes. Two surveys were coded collectively to gain coding consensus. Additional survey data and interview data was coded by two of the authors until a point of saturation was reached.

We have applied a data-coding schema as follows: Participant 1, who completed the survey version 1 of 3 at the beginning of the workshop, is labeled as (P1, S, V1). Pseudonyms and the letter "I" represent the interview data (e.g., Charlie, I).

\section{Results and Discussion}

By comparing the scores from the first and second surveys, we were able to determine the impact of the workshop on perceived self-efficacy (Table 1). By comparing the scores from the second and third surveys, we were able to determine the impact of practice and critical reflection on perceived self-efficacy (Table 2). Of note, parameters that indicated a significant increase in perceived self-efficacy both after the workshop and after practice include: (a) stating goals and learning outcomes clearly for class, (b) motivating student interest in a lecture, (c) using gestures and body language effectively during lectures, and (d) thinking about one's own teaching and making necessary changes to improve it. The control parameter that had no relationship to giving a lecture (Assign grades to students' written assignments or examinations) indicated no significant change after the workshop or after practice $\left(\chi^{2}(2)=4.129, p=0.127\right)$.

In the open-ended survey responses and in the interviews, participants illustrated and reflected on the impact of microteaching-practice and critical reflection-on lecturing self-efficacy. The participant accounts describe lecturing as a broader process that includes lesson planning, engagement within the class time, and critical reflection on the lecture during and after its completion. While all participants observed that practice was integral to building self-efficacy in lecturing, whether participants perceived the workshop practice as "authentic" impacted the extent to which it was deemed relevant, which impacted the extent to which practice built self-efficacy in the actual facilitation of a lecture. Participants also gained self-efficacy in learner-centred lesson planning and in integrating strategies for learner engagement. Finally, participants developed self-efficacy in their lecturing both through practice and through the receipt and offering of peer feedback. In what follows, we consider in greater detail the three thematic areas that speak to how the participants perceived the impact of practice and critical reflection on their view of lecturing. 
Table 1.

Median (Interquartile Range), Direction of Change, and Changes in Participants'Perceived Self-Efficacy After Workshop

\begin{tabular}{|c|c|c|}
\hline Teaching parameter & Before workshop & After workshop \\
\hline Plan an organized lecture & $7(6.5-8)$ & $\begin{array}{c}8(8-9) \uparrow \\
(z=-2.913, p=0.004)\end{array}$ \\
\hline $\begin{array}{l}\text { Overall confidence in your ability to carry out } \\
\text { your responsibilities as a lecturer }\end{array}$ & $7(5 \cdot 5-8)$ & $\begin{array}{c}8(7.5-8) \uparrow \\
(z=-2.640, p=0.008)\end{array}$ \\
\hline Construct clear visual aids (e.g., overheads) & $7(5 \cdot 5-8)$ & $\begin{array}{c}8(7-8) \uparrow \\
(z=-2.636, p=0.008)\end{array}$ \\
\hline $\begin{array}{l}\text { Use gestures and body language effectively } \\
\text { during lectures }\end{array}$ & $7(5.25-7.75)$ & $\begin{array}{c}8(7.25-8) \uparrow \\
(z=-2.588, p=0.010)\end{array}$ \\
\hline Encourage class participation & $7(5-7)$ & $\begin{array}{c}8(7-8.5) \uparrow \\
(z=-2.585, p=0.010)\end{array}$ \\
\hline Motivate student interest in a lecture & $7(5-7)$ & $\begin{array}{c}7(6.5-8) \uparrow \\
(z=-2.434, p=0.015)\end{array}$ \\
\hline State goals and objectives clearly for class & $7(7-8)$ & $\begin{array}{c}8(6.5-8.5) \uparrow \\
(z=-2.309, p=0.021)\end{array}$ \\
\hline $\begin{array}{l}\text { Think about your own teaching and make } \\
\text { necessary changes to improve it }\end{array}$ & $7(4 \cdot 5-8)$ & $\begin{array}{c}8(6.5-8.5) \uparrow \\
(z=-2.264, p=0.024)\end{array}$ \\
\hline $\begin{array}{l}\text { Use videotape feedback to improve your } \\
\text { teaching }\end{array}$ & $6(4-8)$ & $\begin{array}{c}6(4.5-8.5)- \\
(z=-1.725, p=0.084)\end{array}$ \\
\hline Write learning objectives & $7(5 \cdot 5-8)$ & $\begin{array}{c}8(7-8)- \\
(z=-1.622, p=0.105)\end{array}$ \\
\hline Give a lecture & $8(6.5-8.5)$ & $\begin{array}{c}8(7-9)- \\
(z=-1.508, p=0.132)\end{array}$ \\
\hline $\begin{array}{l}\text { Communicate at a level that matches stu- } \\
\text { dents' ability to comprehend }\end{array}$ & $7(6-8)$ & $\begin{array}{c}7(6-8)- \\
(z=-1.265, p=0.206)\end{array}$ \\
\hline $\begin{array}{l}\text { Utilize constructive peer feedback and sug- } \\
\text { gestions to improve your teaching }\end{array}$ & $7(6-8)$ & $\begin{array}{c}7(6.5-8.5)- \\
(z=-0.962, p=0.336)\end{array}$ \\
\hline $\begin{array}{l}\text { Use technology in the classroom (e.g., Power- } \\
\text { Point) }\end{array}$ & $8(6.5-8)$ & $\begin{array}{c}8(7.5-8.5)- \\
(z=-0.791, p=0.429)\end{array}$ \\
\hline $\begin{array}{l}\text { Assign grades to students' written assign- } \\
\text { ments or examinations }\end{array}$ & $7(7-8.5)$ & $8(7-9)-$ \\
\hline
\end{tabular}


Table 2.

Median (Interquartile Range), Direction of Change, and Changes in Participants' Perceived Self-Efficacy After Practice

\begin{tabular}{|c|c|c|}
\hline Teaching parameter & After workshop & After practice \\
\hline State goals and objectives clearly for class & $8(6.5-8.5)$ & $\begin{array}{c}9(8.5-9.5) \uparrow \\
(z=-3.025, p=0.002)\end{array}$ \\
\hline Use videotape feedback to improve your teaching & $6(4.5-8.5)$ & $\begin{array}{c}8(7-9) \uparrow \\
(z=-2.969, p=0.003)\end{array}$ \\
\hline $\begin{array}{l}\text { Utilize constructive peer feedback and suggestions } \\
\text { to improve your teaching }\end{array}$ & $7(6.5-8.5)$ & $\begin{array}{c}9(8.5-9.5) \uparrow \\
(z=-2.825, p=0.005)\end{array}$ \\
\hline Give a lecture & $8(7-9)$ & $\begin{array}{c}9(8-9.5) \uparrow \\
(z=-2.810, p=0.005)\end{array}$ \\
\hline $\begin{array}{l}\text { Use technology in the classroom (e.g., Power- } \\
\text { Point) }\end{array}$ & $8(7 \cdot 5-8.5)$ & $\begin{array}{c}9(8-9) \uparrow \\
(z=-2.810, p=0.005)\end{array}$ \\
\hline Write learning objectives & $8(7-8)$ & $\begin{array}{c}9(8-9) \uparrow \\
(z=-2.804, p=0.005)\end{array}$ \\
\hline $\begin{array}{l}\text { Communicate at a level that matches students' } \\
\text { ability to comprehend }\end{array}$ & $7(6-8)$ & $\begin{array}{c}8(8-9) \uparrow \\
(z=-2.754, p=0.006)\end{array}$ \\
\hline $\begin{array}{l}\text { Think about your own teaching and make neces- } \\
\text { sary changes to improve it }\end{array}$ & $8(6.5-8.5)$ & $\begin{array}{c}9(8-9) \uparrow \\
(z=-2.654, p=0.008)\end{array}$ \\
\hline Motivate student interest in a lecture & $7(6.5-8)$ & $\begin{array}{c}8(8-9) \uparrow \\
(z=-2.565, p=0.010)\end{array}$ \\
\hline $\begin{array}{l}\text { Use gestures and body language effectively during } \\
\text { lectures }\end{array}$ & $8(7.25-8)$ & $\begin{array}{c}9(8-9) \uparrow \\
(z=-2.414, p=0.016)\end{array}$ \\
\hline $\begin{array}{l}\text { Overall confidence in your ability to carry out your } \\
\text { responsibilities as a lecturer }\end{array}$ & $8(7 \cdot 5-8)$ & $\begin{array}{c}9(8-9)- \\
(z=-2.223, p=0.026)\end{array}$ \\
\hline Construct clear visual aids (e.g., overheads) & $8(7-8)$ & $\begin{array}{c}8(8-9)- \\
(z=-2.209, p=0.027)\end{array}$ \\
\hline Encourage class participation & $8(7-8.5)$ & $\begin{array}{c}8(7.5-9)- \\
(z=-2.126, p=0.033)\end{array}$ \\
\hline Plan an organized lecture & $8(8-9)$ & $\begin{array}{c}9(8-9)- \\
(z=-1.732, p=0.083)\end{array}$ \\
\hline $\begin{array}{l}\text { Assign grades to students' written assignments or } \\
\text { examinations }\end{array}$ & $8(7-9)$ & $8(7-9)-$ \\
\hline
\end{tabular}

\section{"How Am I Ever Going to Apply This?": Building Self-efficacy through Au- thentic Practice}

One unexpected result of this study was the way that participants viewed the authenticity and applicability of the practice experience. Participants' conceptions of authenticity and applicability resonated and aligned with Cranton and Carusetta's (2004) definition of authentic practice; that is, critical participation in, and critical knowledge of, context is central to authentic practice. In this research study, participants' critical stance of con- 
text influenced their perception of themselves and of others, and involved several facets, including: (a) the discipline or subject area, (b) the physical space, (c) the community and culture of the participants, and (d) the institutional norms and policies (Cranton, 2006). Participants' conceptualization of a lecture shaped their perception of the applicability of the lecture workshop to future teaching experiences. If participants viewed the practice experience as consistent with their conceptualization of a lecture, their self-efficacy increased. Moreover, several participants who viewed practice within the constraints of the workshop setting as providing relevant skill development described self-efficacy and enthusiasm for future teaching contexts. However, participants who perceived the workshop setting as non-transferrable to the "real" classroom, or inauthentic, expressed concern or feelings of lack of preparation.

In terms of participants' conceptualizations of a lecture, many described a difference between the traditional, didactic lecture and other teaching and learning configurations, such as a seminar, lab, or presentation. For instance, in reflecting on past experience with lecturing, one participant observed: "I guess I facilitated labs, so it's not the same as lecturing” (Mairi, I). Another participant noted: “in the seminar that I taught it wasn't actually teaching I wasn't directly lecturing. I was facilitating the discussion between students and raising some questions for the students to engage" (Charlie, I). This participant considered facilitating discussion as distinct not only from lecturing but also from teaching itself, as teaching in his view necessarily involved direct lecturing. Similarly, another participant described the dissonance in her conceptualization of a lecture: "I see the word lecture and I still see a traditional lecture, but when I stop and say wait a minute, 'What is lecturing?' I guess I wouldn't call it lecturing, you'd call it facilitating a class" (Mairi, I). The distinctions that participants made between facilitation and lecturing also extended to presentations, as one participant noted: "I've done enough presentations and educational things for my research that aren't necessarily lectures but I'm talking to people about my research" (Sarah, I). The ways that participants conceptualized the lecture, or as one participant said: "I guess, it depends how you define 'lecturing" (Mairi, I) was significant, as these definitions shaped how the participants aligned the practice experience of interactive lecturing with the kind of teaching they currently do, and the kind they plan to do, in a classroom setting that they deem congruent with their teaching and learning contexts.

We turn now to authentic practice by considering how participants understood the relationship between lecturing in the workshop context and lecturing in other teaching and learning contexts. For instance, one participant noted increased self-efficacy in giving a lecture: "because I have done it. In some ways it is similar to giving a presentation although a presentation doesn't have as much of the learner engaged component" ( $\mathrm{P} 2, \mathrm{~S}$, $V_{3}$ ). Here the participant made an explicit link to the similarities and differences between their conceptualization of a lecture and a presentation, and the transferability of practice between one context and the other. This transferability between teaching contexts was extended beyond the academic setting by another participant, who noted: "Even if you have no intention on [sic] staying in academia or lecturing that much you have to do presentations and teach all the time in your career so I think that that is a good opportunity" (Sarah, I). Other participants drew self-efficacy from the experience of participating as learners in the practice lectures of peers, noticing that "part[s] of the skills transferred" regardless of "particular subject matter" (Ted, I). 
While some participants made the link between practice and authentic contexts, other participants did not make this connection, finding the artificial constraints of the workshop setting negatively impacted their self-efficacy or did not offer skills that were transferable to other teaching contexts. Speaking to the time constraints of the practice sessions, one participant noted: "the ten minute slots were too small, so it actually left me feeling very stressed going into the [real] one I had planned because I had a three hour lecture that I was giving" (Clara, I). For this participant, the constraint of delivering a 10-minute lesson distracted from transferable skills being developed because the focus was on the inauthenticity of the time limit. Similarly, another participant noted that while "standing up and giving a 10 or 12 minute presentation is putting into practice more than not doing a presentation, it still lacks a certain level of realism, like the realism of actually standing up and giving a lecture or facilitating a class" (Mairi, I). This participant made the distinction between having some practice and having no practice, and refuted the aphorism that "some experience is better than no experience" by observing that it still lacks realism. In this instance, some practice was the same as no practice: practice in this context did not provide the desired authenticity of the classroom experience.

Without the understanding that the practice context provides transferable skills to the authentic teaching context, some participants did not make the implicit link between practice and practical application. One area for further reflection is why some participants were able to identify transferable skills developed in the practice context, indicating: "I'll be trying to apply that in the future especially if I go back home I will be doing lots of lecturing so I will be trying to apply all of the skills and all of the techniques that will be appropriate for the students to be engaged in as well" (Michael, I), while other participants found they had more "foundational knowledge, but a practical application is still lacking" (Mairi, I).

Just as one participant suggested that other graduate students should have the opportunity to take part because "it would pretty much help the quality of teaching and even just research presentations" (Ted, I), we see transferable skills to both future teaching contexts and other current teaching contexts. What remains, then, is to make these implicit areas of application explicit and perceptible to all participants.

\section{Shifting the Focus: Learner- and Self-centredness}

Learner-centredness, described in the workshop as an intentional focus on the active engagement of learners and the development of metacognitive awareness, was particularly evident with respect to lesson planning, where participants reported experiencing a shift from a focus on content to a focus on process. Self-centredness or concern for self was a common pattern in the data and pointed to how participants' teaching skills were being perceived by students.

Learner-centredness was conceptualized by participants in the following ways: (a) scaffolding material, (b) constructively aligning learning outcomes, (c) engaging classroom activities and assessment methods, and (d) facilitating learning rather than directly transmitting information. By focusing on learner-centredness, participants were able to make informed, evidence-based decisions about their lecturing approach, leading to an increase in their self-efficacy. 
Several participants identified constructive alignment as a framework that they will explicitly consider and incorporate in their future teaching practice. As one student noted: "it will be my own duty to choose the best method of active learning and how to match it to the content or to align the objectives or outcomes with content and the exam itself" (Michael, I). Another student linked constructive alignment back to the workshop practice component when they said: "And to show yourself that in such a short little presentation you can design objectives and meet those objectives and get people actively involved" (Mairi, I). Here, the participant was able to effectively utilize the practice component of the workshop to demonstrate not only that they can write, but also that they can fulfill their learning outcomes through active student engagement. Lastly, learner-centredness was related to a more facilitative approach that focuses on students being active participants in their learning. One participant noted: "it's the student's job, onus, to understand the material. And it's not your job to necessarily just give them the information, but it's their job to assimilate and understand and apply more than just you, lecturing" (Mairi, I). Another student echoed this sentiment: "I shouldn't focus on giving all the information to the students. I should focus on giving them the main issues, the main information, the main themes" (Charlie, I). Yet another participant stated: "I am not going to do the direct transmission method of delivering the [sic] lecturing" (Michael, I). These participant accounts emphasized a certain way of thinking about lecturing as facilitating students' active engagement with the material, as opposed to passively receiving information. Together, participants' discussion of scaffolding material, constructive alignment, and active facilitation demonstrated commitment and self-efficacy in taking a learner-centred approach in their teaching practice.

The lecturing workshop series also highlighted self-centredness, or concern for self. Participants viewed the practice component as an opportunity to enhance their skills in a less intimidating environment than the classroom. For instance, one participant noted: “The stakes look to be much lower when you're already in front of a class and you're teaching so I mean then you're professionally on the spot if you do something, screw it up. You technically screwed up a class" (Ted, I). Another stated:

So it gives you an opportunity to just really focus on your presentation skills and not the subject matter which is a unique experience because a lot of times in lecturing you're so worried about the subject matter that you don't necessarily focus on how to be engaging and stuff like that stuff comes later (Sarah, I).

Both of these participant accounts highlighted a concern for self, in terms of being able to teach students effectively. Other participants talked about how students perceived or reacted to them in more general terms. One noted:

My feeling right now at least is that there's no way that I can please an entire room of students at one time, but over the course of the semester I can probably make most of them pretty happy. I think (Clara, I).

Another participant offered his perception of whether or not a particular teaching approach was effective: "Sometimes the approach work[ed], sometimes it didn't work. It depends on the students' number, the students levels', the students' acceptability of the 
way I'm doing it" (Michael, I). In these instances, a concern for self was manifested as a desire to be pleasing or acceptable to students.

This juxtaposition of learner-centredness and self-centredness is important to consider in future iterations of the lecturing workshop series. Although the intent was to promote a learner-centred approach to teaching and to provide opportunities to practice this approach, it is important to be conscious of participants turning the focus on themselves and how they are being perceived. A consideration for the learner-centred position of the lecturer, which is to say their metacognitive awareness of their role, emerged as a result of this research study; the interviews provided an outlet for further reflection through conversation and made room for the self as learner. In light of the data, subsequent workshops should intentionally value the learning process in relational ways, as participants make new and personally meaningful interpretations of their experience of learner-centred lecturing.

\section{You're Better than You Think: Peer-based Learning}

The data revealed that feedback and critical discourse among peers contributed greatly to the quality of the lecturing workshop experience and enhanced participants' perceptions of their abilities to facilitate a learner-centred lecture. In the lecturing workshop series, feedback was immediately received from the instructor and from peers. Participants were also videotaped so they could self-reflect on how they facilitated their lesson once the workshop was completed. The immediacy of the feedback was particularly valuable to participants. As one participant stated: "Erin took five minutes to talk to us immediately after which I think the feedback that way was super, super helpful" (Clara, I). Another participant commented: "But I do remember getting, so Erin gave me some really good comments, right away" (Mairi, I). Both participants recalled and commented on the importance of receiving immediate feedback. This appreciation for immediacy did not come as a surprise, as the importance of timely feedback is well documented in the scholarly literature on teaching and learning. For example, Nicol and Macfarlane-Dick (2006) and Chickering and Gamson (1987) similarly espoused timely feedback as a good teaching practice. The data confirmed that timely feedback from peers and from the instructor was one of the strengths of the lecturing workshop series and contributed to a perceived increase in self-efficacy.

Participant accounts also highlighted the importance of peer feedback with respect to increasing their self-efficacy. As one participant stated: "I think that the big strength with the lecturing workshop series is the fact that you get a lot of feedback from your peers and that you get to learn from others" (Sarah, I). Peer feedback was particularly important in constructively contradicting negative self-conceptualizations in ways that led to increased selfefficacy. Several participant accounts highlighted this. For example, one participant noted:

I think that helps build confidence because sometimes when you watch it [video] you're really tough on yourself like "Oh my god. I can't believe I'm like this." But that if it works for other people and it's engaging for them then that helps build your confidence. (Sarah, I) 
Another participant commented: "[It's] good to see that everybody did a lot better than they thought. You know I think you're more internally nervous doing those things than you actually come across" (Mairi, I). Yet another participant echoed a similar sentiment: "the video and feedback was very helpful because I realized although I can still improve, it is not as distracting as I had thought." ( $\left.\mathrm{P} 1, \mathrm{~S}, \mathrm{~V}_{3}\right)$. These comments illustrate that some workshop participants were more critical and held more negative perceptions of themselves compared to their peers. One participant noted: "It [tone of voice] is a personal concern. But for my peers who were observing me, for Erin, she said 'No that was fine. You actually don't suffer from this, from what you think" (Charlie, I). By receiving peer feedback that contradicted their internal criticisms, participants were able to challenge the accuracy of their self-perceptions such that their self-efficacy increased.

Peers were also important for learning from one another, as participants were able to watch each other give 10-minute lectures. One participant noted: "I got a lot from my peers, different techniques of engaging us" (Michael, I). Another participant was able to identify a specific engagement technique: "And then something that I didn't get a chance to do in my ten minute one but that I had seen other people do in that session is the one minute feedback" (Clara, I). Some participants were able to immediately incorporate lessons learned by watching peers: "I was in the middle so I saw the beginners who started so I tried to get advantages from what they do and to avoid what's the disadvantages" (Michael, I). Peer-based learning was linked by one participant to a positive workshop climate where they felt comfortable to take risks: "And especially because it's a very nonjudgemental context because everyone is here to see what works and what doesn't and it's OK to just screw something up" (Ted, I). These participant accounts illustrate the value of learning from one's peers, and highlight that participant learning takes place both by doing (giving a 10-minute lecture) and by observing others.

Participants indicated that the role of peers, in giving feedback that counters negative self-criticism and in modelling how to facilitate an engaging lecture, was a central component of the lecturing workshop series and important to increasing self-efficacy in lecturing. Future iterations may expand upon these components by explicitly talking about the value that each participant brings to the workshop experience.

This case study of a small sample of graduate students highlighted several pedagogical principles that can be transferred and extended to other educational development and classroom contexts. These principles are: (a) opportunities to apply theoretical principles in practice, (b) iterative experiential teaching cycles with the support of peer and instructor feedback, (c) space and time for dialogue and personal, critical reflection, and (d) an intentional approach that recognizes the importance of considering the contextualization and operationalization of theoretical constructs, such as learner-centredness. In future research, the impact of TA and instructor self-efficacy on student learning warrants further consideration.

Another lecture series was offered in the spring of 2015, with a similar time frame, topic, and group size from the previous year, and was facilitated by educational developer, Meagan Troop. During the process of preparing and facilitating the lecture series, Erin Aspenlieder and Meagan Troop met to critically dialogue and reflect on the (re)shaping of this teaching and learning experience. Specific changes included providing time and space within the initial workshop for participants to actively experiment with expressive indicators (i.e., voice, 
gesture, space) in pairs. Participants were also given the choice to re-teach an aspect of their lesson following the initial microteaching cycle and to focus on improving one aspect of their lesson based on feedback. These two examples illustrate some of the programming improvements that were made at the workshop level in an effort to offer innovative experiences as part of the University of Guelph's graduate teaching development program.

\section{Summary}

The impact of practice teaching relative to the typical workshop experience indicated that there were significant learning gains associated with microteaching cycles that involved self, peer, and instructor feedback. The survey data revealed an increase in selfefficacy for all of the participants as a result of the practice teaching and critical reflection components; a finding that was further confirmed by participant accounts gathered through qualitative interviews. While the typical workshop setting offers a good introduction to a teaching topic or issue, this study highlights the need for mobilizing theory into practice to leverage learner strengths and build teaching capacity. Our study highlights the dialectic experience for graduate students involved in teaching development, and speaks to an integrated, interdisciplinary approach that promotes learner-centredness in the context of program development.

\section{References}

Aspenlieder, E., \& Rawn, C. D. (2014). STLHE Green Guide No 14. Teaching graduate students to teach. London, Canada: Society for Teaching and Learning in Higher Education.

Bandura, A. (1977). Self-efficacy: Toward a unifying theory of behavioural change. Psychological Review, 84(2), 191-215.

Boman, J.(2013). Graduate student teaching development: Evaluating the effectiveness of training in relation to graduate student characteristics. Canadian Journal of Higher Education, 43(1), 100-114.

Boman, J. (2008). Outcomes of a graduate teaching assistant training program (Doctoral dissertation). The University of Western Ontario, Canada.

Bresler, L., \& Stake, R. E. (1992). Qualitative research methodology in music education. In R. Colwell, (Ed.), Handbook of research on music teaching and learning (pp. 75-90). New York: Schirmer Books.

Chickering, A. W., \& Gamson, Z. F. (1987). Seven principles for good practice in undergraduate education. AAHE Bulletin, 3-7.

Cranton, P. (2006). Understanding and promoting transformative learning: A guide for educators. (2nd ed.). San Francisco: Jossey-Bass.

Cranton, P., \& Carusetta, E. (2004). Developing authenticity as a transformative process. Journal of Transformative Education, 2(4), 276-293.

deWinstanley, P. \& Bjork, R (2000). Successful learning: Presenting information in ways that engage effective processing. In D. F. Halpern \& M.D. Hakel (Eds.), Applying the science of learning to university teaching and beyond (pp. 19-31). New Directions for Teaching and Learning, No. 89. San Francisco, CA: Jossey-Bass. 
Dimitrov, N., Meadows, K, Kustra, E., Ackerson, T., Prada, L., Baker, N., Boulos, P., McIntyre, G., \& Potter, M. K. (2013). Assessing Graduate Teaching Development Programs for Impact on Future Faculty. Toronto: Higher Education Quality Council of Ontario.

Friedman test in SPSS statistics. (2013). Laerd Statistics. Retrieved from https:// statistics.laerd.com/spss-tutorials/friedman-test-using-spss-statistics.php

Grabove, V., Kustra, E., Lopes, V., Potter, M. K., Wiggers, R., \& Woodhouse, R. (2012). Teaching and learning centres: Their evolving role within Ontario colleges and universities (Issue Paper No. 12). Toronto: Higher Education Quality Council of Ontario.

Gibbs, G. (2007). Analyzing qualitative data. Thousand Oaks, CA: Sage.

Heenan, T., \& Jerich, K. (Eds.) (1993). Teaching graduate students to teach: Engaging the disciplines. Champaign, IL: Office of Conferences and Institutes.

Knight, J. K., \& Wood, W. B. (2005). Teaching more by lecturing less. Cell Biology Education, 4(4), 298-310.

Loughran, J. (2002). Effective reflective practice: In search of meaning in learning about teaching. Journal of Teacher Education, 53, 33-43. doi:10.1177/0022487102053001004

McCombs, B. L., \& Whisler, J. S. (1997). The learner-centered classroom and school. San Francisco: Jossey-Bass.

Miles, M. B., \& Huberman, A. M. (1994). Qualitative data analysis: An expanded sourcebook. London: Sage.

Moustakas, C. (1994). Phenomenological research methods. Thousand Oaks, CA: Sage.

Nicol, D. J., \& Macfarlane-Dick, D. (2006). Formative assessment and self-regulated learning: A model and seven principles of good feedback practice. Studies in Higher Education, 31(2), 199-218.

Patton, M. Q. (2002). Qualitative research \& evaluation methods (3rd ed.). Thousand Oaks, CA: Sage.

Prieto, L. R., \& Altmaier, E. M. (1994). The relationship of prior training and previous teaching experience to self-efficacy among graduate teaching assistants. Research in Higher Education 35(4), 481-497.

Prieto, L. R., \& Meyers, S. A. (2001). The teaching assistant training handbook: How to prepare TAs for their responsibilities. Stillwater, OK: New Forums Press.

Prince, M. (2004). Does active learning work? A review of the research. Journal of Engineering Education, 93(3), 223-231.

Salinas, M. F., Kozuh, G. \& Seraphine, A. E. (1999). I think I can: Improving teaching self-confidence of international teaching assistants. Journal of Graduate Teaching Assistant Development, 6(3), 149-156.

Schunk, D. H. (1991). Self-efficacy and academic motivation. Educational Psychologist, 26, 207-231.

Shannon, D. M., Twale, D. J., \& Moore, M. S. (1998). TA teaching effectiveness. The Journal of Higher Education, 69, 440-466. 
University of Guelph. (2014). 2014-2015 Undergraduate Calendar. Retrieved from: https://www.uoguelph.ca/registrar/calendars/undergraduate/2014-2015/

Van Note Chism, N. (1998). Evaluating TA programs. In M. Marincovich, J. Prostko, \& F. Stout (Eds.) The professional development of graduate teaching assistants (pp. 249263). Bolton: Anker Publishing.

Weimer, M. (2002). Learner-centred teaching: Five key changes to practice. San Francisco: Jossey-Bass.

Wilson, K. \& Korn, J. (2007). Attention during lectures: Beyond ten minutes. Teaching of Psychology, 34(2), 85-89.

\section{Contact Information}

Meagan Troop

University of Waterloo

megtroop@gmail.com

Meagan Troop is an Online Learning Consultant at the University of Waterloo and an adjunct instructor at Laurier's Faculty of Education. She plays a collaborative role in designing and supporting curricular development for undergraduate and graduate level programming. Meagan's research interests include faculty and graduate student development and creative pedagogy.

Lauren Wallar is a PhD candidate in Population Medicine at the University of Guelph, and an educational development specialist at York University. Her interests include interdisciplinary approaches to science education and supporting metacognitive skill development.

Erin Aspenlieder is an educational developer at the University of Guelph. She supports graduate student teaching development, as well as curricular and scholarship of teaching and learning initiatives. Her research interests include teaching support for contingent instructors, neoliberalism in higher education, and graduate student professional development. 


\section{Appendix: Data Collection Instruments and Codes \\ Modified TA Self-Efficacy Scale}

Please rate how confident you are in your ability to be effective in each of the following teaching skills and behaviours on a scale from 1 to 10 . Write the number that best reflects your confidence level in the space provided.

If you were given the opportunity to perform the following teaching tasks, please rate how confident you would be in your ability to accomplish these tasks.

$\begin{array}{llllllllll}1 & 2 & 3 & 4 & 5 & 6 & 7 & 8 & 9 & 10\end{array}$

not confident ${ }^{*} \quad$ somewhat confident ${ }^{*} \quad$ completely confident $^{*}$

\section{How confident are you in your ability to...}

1. 1. state goals and objectives clearly for class

2. 2. motivate student interest in a lecture.

3. 3. communicate at a level that matches students'

ability to comprehend

1. 4. give a lecture

2. 5. plan an organized lecture

3. 6. use technology in the classroom (e.g., Powerpoint)...

4. 7. assign grades to students' written assignments or

examinations

1. 8. use videotape feedback to improve your teaching...

2. 9. construct clear visual aids (e.g., overheads)

3. 10. utilize constructive peer feedback

and suggestions to improve your teaching.

1. 11. use gestures and body language effectively during

lectures.

1. 12. write learning objectives.

2. 13. encourage class participation

3. 14. think about your own teaching and make necessary

changes to improve it.

1. 15. Overall, how confident are you in your ability to carry out your responsibilities as a lecturer? 


\section{Interview Questions}

Information about these interview questions: This information gives you an idea of what I would like to learn about your understanding of lecturing and your experience of the lecture workshops. Interviews will be one-to-one and will be semi-structured. Because of this, the exact wording may change a little. I will begin with the questions listed on your sheet. On occasion I will use other short questions to make sure I understand what you have told me or to confirm and probe further, such as: "So, you are saying that ...?), to get more information ("Please tell me more?"), or to learn what you think or feel about something (“Why do you think that is...?”).

1) Information about you: What program are you presently enrolled in? What year of your program are you in? What other teaching development opportunities have you taken part in?

2) Please tell me about your experience with lecturing.

3) Please tell me about your experience with lecturing with respect to your confidence while lecturing.

4) Please tell me about your experience with the lecturing workshop series.

5) Do you think the lecture workshop series you participated in increased your confidence in giving a lecture?

[ ] Yes [ ] No Please tell me more about why you think that?

5) What key ideas or skills did you develop by taking part in the lecture workshop series?

Yes [ ] No [ ] Please tell me more about why you think that?

6) Would you want other graduate students to take part in the lecture workshop series?

[ ] Yes If yes, please tell me more.

[ ] No If no, please tell me more.

7) Is there something important we forgot? Is there anything else you think I should know about your experience of the lecture workshops? 


\section{Interview Questions}

$\begin{array}{ll}\text { Assessment } & \text { Feedback } \\ \text { \#assessment } & \text { \#constructive } \\ \text { \#assessmentforlearning } & \text { \#diagnostic } \\ \text { \#subjectmastery } & \text { \#encouragement } \\ \text { \#summative } & \text { \#modelling } \\ & \text { \#formative } \\ \text { Authentic Experience } & \text { \#feedback (positive and negative) } \\ \text { \#authenticity } & \text { \#peer feedback } \\ \text { \#enabling constraints (macro, micro) } & \text { \#student feedback } \\ \text { \#relevance } & \\ \text { \#experiential learning } & \text { Future Application } \\ & \text { \#experience (lack, plenty, past) } \\ \text { Concern for Self } & \text { \#theory-practice } \\ \text { \#anxiety } & \text { \#future } \\ \text { \#benchmark } & \text { \#goals } \\ \text { \#concern for self } & \text { \#transfer (of skills) } \\ \text { \#confidence } & \\ \text { \#embodiment } & \text { Learning for Participant } \\ \text { \#perception } & \text { \#skill development } \\ \text { \#self-efficacy } & \text { \#intrinsic motivation } \\ & \text { \#life long learning } \\ \text { Constructive Alignment/Learner- } & \text { \#motivation } \\ \text { Centered } & \text { \#formal training } \\ \text { \#alignment } & \\ \text { \#cognitive load } & \text { Lecture Concept } \\ \text { \#constructive alignment } & \text { \#lecture concept } \\ \text { \#learner-centred } & \text { \#nontraditional teaching } \\ \text { \#scaffolding } & \\ \text { Contextual Factors } & \text { Lesson Planning } \\ \text { \#class size } & \text { \#agenda } \\ \text { \#disciplinary } & \text { \#format } \\ \text { \#discipline } & \text { \#learnerpreferences } \\ \text { \#interdisciplinary } & \text { \#lesson plan } \\ \text { \#time constraint } & \text { \#sequence } \\ \text { \#time management } & \text { \#structure } \\ & \text { \#threshold concepts } \\ & \\ & \\ & \end{array}$




\section{Reflection}

\#critical reflection

\# reflection

\# reflection-in-action

\#self-awareness

\#self-recognition

\#metacognition

Outcomes

\#objectives

\#outcomes

\section{Peer Based Learning}

\#peer-based learning

\#zone of proximal development

\section{Practice}

\#practice

\# rehearsal

\#risk taking

\#trial and error

\section{Presentation}

\#multi-media

\#technology integration

\#non-verbal communication

\#pace

\#presentation skills

\#verbal communication

\section{Student Engagement}

\#active learning

\#classroom assessment techniques

\#distraction

\#participation

\#pedagogies of engagement

\#strategies

\#student engagement

\#student interest

\section{Teaching Philosophy}

\#teaching philosophy

\#didactic

\#teaching persona

\#self-conceptualization

\#facilitation

\#instructor enthusiasm

\#flexibility

\#tone of teaching

\section{Scholarship of Teaching and Learning}

\#pedagogical language

\# evidence based

\#scholarly practice

\#pedagogy

\#SoTL 